\title{
Model of connecting an airport by rail - case study: the city of Zagreb
}

\author{
T. Mihetec, M. Petrovic \& M. Starcevic \\ Faculty of Transport and Traffic Sciences, University of Zagreb, Croatia
}

\begin{abstract}
Zagreb Airport is a distance of $15 \mathrm{~km}$ away from the City of Zagreb itself. It is connected with the City by road, which is congested during the morning and afternoon peak hours of commuting transport, thus significantly affecting the travel time to and from the airport. The airport development plan for the next 20 years includes the construction of another runway and a new passenger terminal of higher capacity for passenger handling and an adequate level of equipment. Regarding the planned increase in traffic at Zagreb Airport, it is necessary to expand the infrastructure capacities that connect the centre of Zagreb and Zagreb Airport, since already the existing capacities are insufficient. The current connection of the airport with the city is exclusively by road; more precisely, the main road that connects the city of Velika Gorica with Zagreb, and which is one of the busiest roads in the Republic of Croatia, and already as such cannot meet Zagreb Airport's requirements.

Since the railway line that connects the cities of Zagreb and Velika Gorica passes within the vicinity of the airport, the plan is to connect Zagreb Airport to the existing railway infrastructure and to construct an underground stop under the passenger terminal. This paper does not focus on the infrastructural solutions, but rather on the operator model, i.e. a rail carrier that would provide adequate transport of passengers in relation to Zagreb-Zagreb Airport-Velika Gorica.

The paper will analyze the current state regarding the number of passengers and the methods of arriving, i.e. leaving the airport. Regarding the expected number of passengers in the future and the construction of an underground railway stop, a railway carrier model will be provided. The model will encompass the dimensions of the mobile capacities, i.e. transport means, the rail carrier trip frequency (headways), and the introduction of an integrated transport document for the purpose of more comfortable travel.
\end{abstract}

Keywords: railway, airport, mobile capacity, headway, model. 


\section{Introduction}

Airport capacities depend on air traffic control, runways, taxiways, the terminal, the apron and airport surface access. Restrictions imposed in any of the mentioned elements have significant repercussions on the efficient operation of the airport. Since 1970 air transport has doubled every ten years in the world, thus causing policy makers and planners to turn to increasing the capacities of runways and airport terminal areas in order to meet the ever growing transport demand. Only since the 1990s has airport surface access become one of the critical components of the air transport system.

The growth of air transport, including airports, requires further development of surface access to the airport facilities, in order to meet the increasing demand. Airports should be efficiently connected to the market (wider airport environment) they serve. The facilities and services provided by the airports may include access to the airport by road, rail or other transport modes. The employees working at airport facilities have different requirements, but still the "carpooling" methods need to be taken into consideration. The balance should be achieved by meeting the airport user requirements, taking into consideration the local transport needs, means and priorities.

The urbanization around the airports and the growth in the number of transport means on airport access routes have increased the traffic congestion, reduced the reliability of airport connection and increased the environmental degradation. Apart from the already present road traffic, the precondition for further airport development and increase of capacities (landside, airside) lies also in good infrastructural connection of the rail and public transit. Regarding the predicted growth in air traffic, the experts emphasize that the solution of the airport access issue will be crucial for the airport managers and policy makers in order to satisfy the future growth.

A large number of airports support the usage of rail transport in order to serve a maximally wide catchment zone. Good examples of various airport access solutions using rail transport include:

- $\quad$ Metro in Madrid and Stuttgart,

- high-speed networks at Frankfurt, Charles de Gaulle, Copenhagen,

- $\quad$ light urban rail in Washington/Baltimore; Bremen,

- high-speed dedicated at Heathrow, Oslo, Stockholm, Hong Kong, Kuala Lumpur

\section{Zagreb Airport - current situation}

Zagreb Airport was founded at the beginning of the 1960s, motivated by the impossibility of the then airport Lučko to accommodate modern jet aircraft that 
landed exclusively on constructive pavement runways. The passenger building built at the beginning of $1960 \mathrm{~s}$ is $60 \mathrm{~m}$ wide and since there was no possibility of being extended in that direction, it was developed into the length reaching 200 metres. Zagreb Airport was designed as a combined civil-military airport, with a single runway, the civil one, being used also by military aircraft. Today, Zagreb Airport represents a rare example in Europe, with the airport representing also an airbase. In Europe, about two thirds of airports of capital cities have two and more runways, and only some ten of them justify this fact by the traffic volume. Mainly the airports of cities generated by the disintegration of the Soviet Union and Yugoslavia feature a single runway.

The South-east of Europe has currently 19 commercial airports (Table 1) that provide scheduled air transport. It should be noted that the majority of airports in the region are sufficiently close to the national borders to be used also by the neighbouring countries. Zagreb and Belgrade represent the main airports in the region and provide transfer flights. Still, the South-east of Europe lacks a central hub. Vienna, Milan and Munich represent airports that provide hub services to the South-east of Europe. With 2.6 and 2.2 million passengers in 2008, Belgrade and Zagreb remain relatively small airports in the European frames.

Table 1: $\quad$ Primary airports in the SEE region.

\begin{tabular}{|l|c|c|c|c|c|}
\hline \multirow{2}{*}{ Airport } & \multicolumn{3}{|c|}{ Passengers } & \multirow{2}{*}{ Index 08/06 } & $\begin{array}{c}\text { Runway } \\
\text { le ngth }\end{array}$ \\
\cline { 2 - 5 } & $\mathbf{2 0 0 8}$ & $\mathbf{2 0 0 7}$ & $\mathbf{2 0 0 6}$ & & 3.400 \\
\hline Belgrade & 2.650 .048 & 2.512 .890 & 2.222 .445 & 119 & 3.252 \\
\hline Zagreb & 2.192 .453 & 1.992 .445 & 1.728 .413 & 127 & 2.750 \\
\hline Tirana & 1.267 .041 & 1.107 .325 & 906.103 & 140 & 2.550 \\
\hline Split & 1.203 .778 & 1.190 .551 & 1.095 .852 & 110 & 3.300 \\
\hline Dubrovnik & 1.191 .474 & 1.143 .168 & 1.120 .453 & 106 & 2.500 \\
\hline Prishtina & 1.130 .640 & 990.259 & 882.731 & 128 & 2.450 \\
\hline Skoplje & 652.339 & 626.644 & 542.319 & 120 & 2.500 \\
\hline Tivat & 608.000 & 574.011 & 451.289 & 135 & 2.600 \\
\hline Sarajevo & 506.398 & 505.269 & 466.186 & 109 & 2.500 \\
\hline Podgorica & 501.113 & 460.020 & 381.847 & 131 & \\
\hline TOTAL: & $\mathbf{1 1 . 9 0 3 . 2 8 4}$ & $\mathbf{1 1 . 1 0 2 . 5 8 2}$ & $\mathbf{9 . 7 9 7 . 6 3 8}$ & $\mathbf{1 2 3}$ & \\
\hline Vienna & $\mathbf{1 9 . 7 4 7 . 2 8 9}$ & $\mathbf{1 8 . 8 0 0 . 0 0 0}$ & $\mathbf{1 7 . 0 0 0 . 0 0 0}$ & $\mathbf{1 1 6}$ & $\mathbf{3 . 6 0 0}$ \\
\hline
\end{tabular}

Until 1991 Zagreb Airport was the main transit transfer airport in the region of the former Yugoslavia with the highest traffic volume realised in 1979, with 1.9 million passengers yearly, out of which 0.4 million were in transit (passengers who continue their journey on the same flight) and about 0.8 million in transfer (passengers who change flights). Zagreb Airport, with a traffic of $\sim 2$ million passengers in 2008, when this is compared to 4,874 billion passengers in the world, represents about $0.41 \%$ of global traffic at airports (in 1979 about $1 \%$ ). With about 3\%o of transfer passengers, Zagreb Airport has lost its status of hub or transit-transfer airport. 


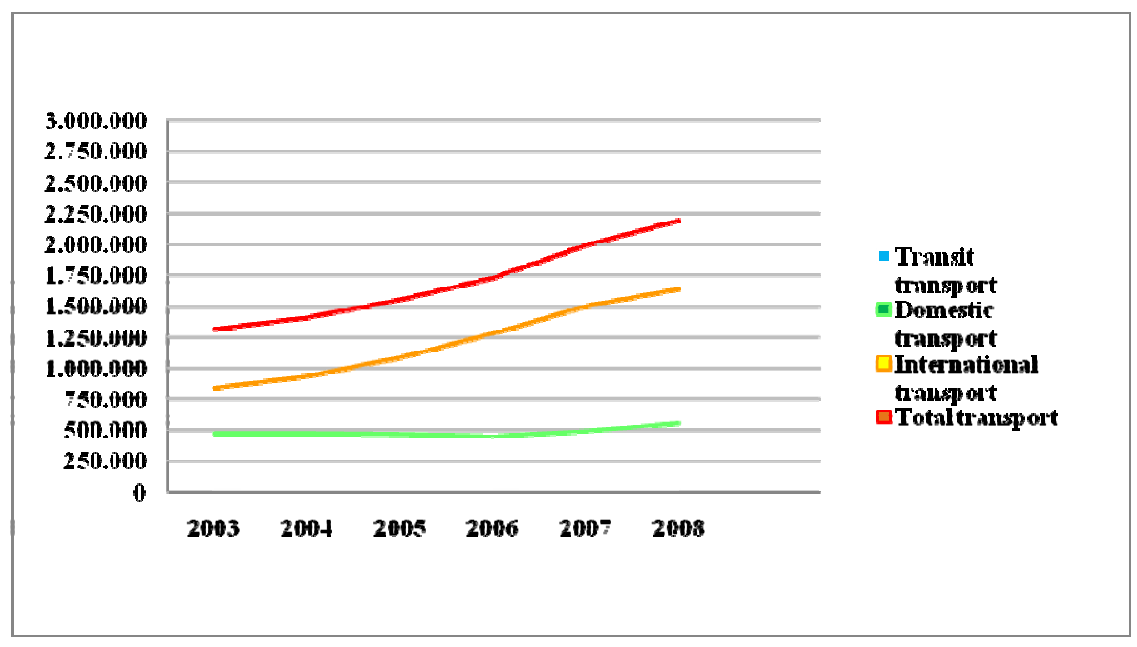

Figure 1: Annual growth of passengers at Zagreb Airport.

Whereas Zagreb Airport experienced slow development, other airports around it took advantage of the European environment and multiplied their traffic many times. With 1.5 million passengers Ljubljana came close to Zagreb (in 1979 Ljubljana realized only a third of Zagreb traffic), Graz handled 1 million passengers (in 1979 - a fifteenth of Zagreb traffic), Budapest about 8.5 million passengers or four times more than Zagreb (in 1979 this amount was below the Zagreb level), Prague with 12.7 million passengers realized six times more traffic than Zagreb (in 1979 Prague was slightly above Zagreb level), and Vienna realized more than 19.7 million passengers in 2008, or nine times more compared to Zagreb (in 1979 Vienna handled less than 4 million or twice as much as Zagreb).

\section{Airport connection with Zagreb}

Currently, the Airport is connected with the rest of the city exclusively by road, that is, state road D30 which has the primary role of connecting the City of Zagreb, via Velika Gorica and Petrinja with the state border Hrvatska Kostajnica. (Figure 2)

This state road is one of the busiest roads in the Republic of Croatia. According to the statistics of the Croatian Roads the section between Zagreb and Velika Gorica occupies the third place regarding traffic load (Table 2). This results in the problem of traffic connection of the Airport users (passengers, employees) with the city centre because of traffic congestion on this road, especially during morning and afternoon peak hours.

At the moment, the Airport is not connected with the rest of the city by rail in spite of the fact that the railway line passes close by the airport.

The very centre of Zagreb is $16.5 \mathrm{~km}$ away from Zagreb Airport and the trip takes on the average about 20 minutes in off-peak hours. For the purposes of this 


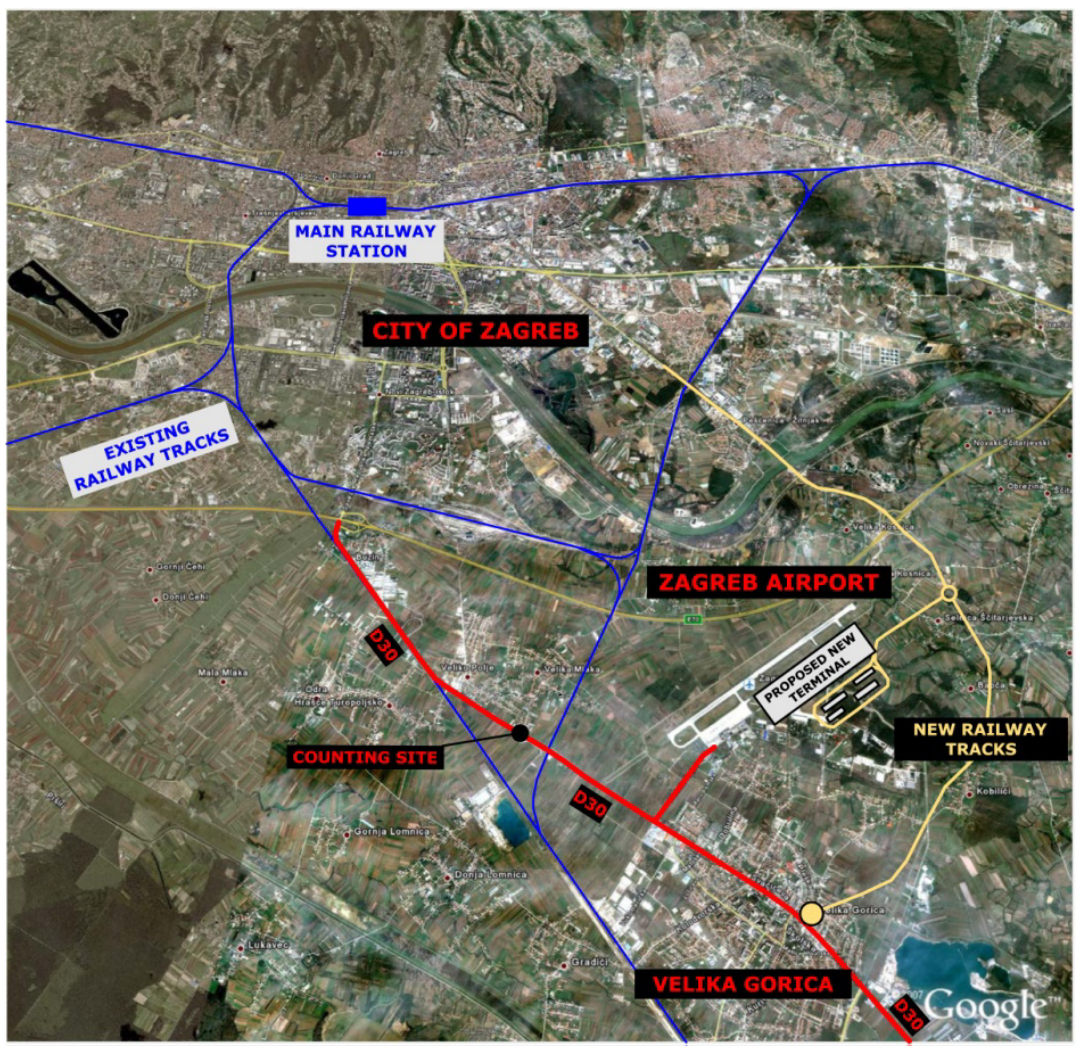

Figure 2: $\quad$ Location of Zagreb Airport.

Table 2: $\quad$ Top five state highways by traffic load in 2008 .

\begin{tabular}{|l|l|c|}
\hline $\begin{array}{c}\text { ROAD REFERENCE } \\
\text { NUMBER }\end{array}$ & COUNTING SITE & AADT \\
\hline D8 & Stobreč & 49682 \\
\hline D8 & Solin & 44263 \\
\hline D30 & Velika Mlaka & 42061 \\
\hline A1 & Lučko - south & 32146 \\
\hline A1 & Jastrebarsko - south & 29914 \\
\hline A1 & Ivanja Reka - east & 26404 \\
\hline
\end{tabular}

AADT (Average Annual Daily Traffic). 
work, studies were carried out on site in a period of one week. Every day in the week, the vehicle travelled along the route from the city centre to Zagreb Airport and back during morning and afternoon peak hours, i.e. in the morning between 7.30 and 8.30 a.m. and in the afternoon between 4.00 and 6.00 p.m. Apart from peak loads, the measurements were also carried out every day at randomly selected time intervals outside the peak load intervals. During peak hours, the average travel time was 38 minutes, which is rather long regarding the relatively short distance to Zagreb Airport from the city centre.

The national flag carrier Croatia Airlines (Pleso transport) offers their passengers the possibility of using shuttle-buses between Zagreb and Zagreb Airport with the schedule being adjusted to the company's flying schedule. Every day, from Monday to Sunday 24 buses operate between Zagreb Airport and Zagreb and 30 buses operate in the opposite direction. Apart from the mentioned regular departures, there are also special bus lines for scheduled CA flights. The buses depart from the city centre to Zagreb Airport 90 minutes prior to aircraft take-off for domestic flights and 120 minutes for international flights, and from Zagreb Airport to the city after aircraft landings of scheduled CA lines. Apart from carrying CA passengers the buses also carry CA crew members, Zagreb Airport employees, Zagreb customs office employees, and Croatia Control employees.

This leads to the conclusion that the passengers may reach the airport by taxis, passenger cars, buses and rent-a-cars. Regarding taxis, the passengers have available 67 vehicles located in front of the terminal building and each of these vehicles performs daily two to three rides. The peak hours are between 07.00 and 08.30 a.m. and 11.00 a.m. and 03.00 p.m.

\section{Rail carrier model}

According to ICAO, the planning phase needs to include full analysis of the airport connection with the rail infrastructure - required rail operator capacity that could meet the terminal landside or airside capacity of the Airport. The demand for rail connection of the airport and the served metropolitan area is generated by: incoming and outgoing passengers, meeters and greeters, employees from the airport and from other industries located within the airport area (airport support and supply services), and other visitors (including those who arrive for shopping or a business appointment). According to the type of connection, there are several types of rail connections: metro rail, high speed dedicated, regional and national, and light rail.

The decision on connecting the metropolitan area and the airport by rail depends on several factors, particularly:

the annual number of airport passengers,

the connection possibilities to the already existing traffic infrastructure (road and rail). 


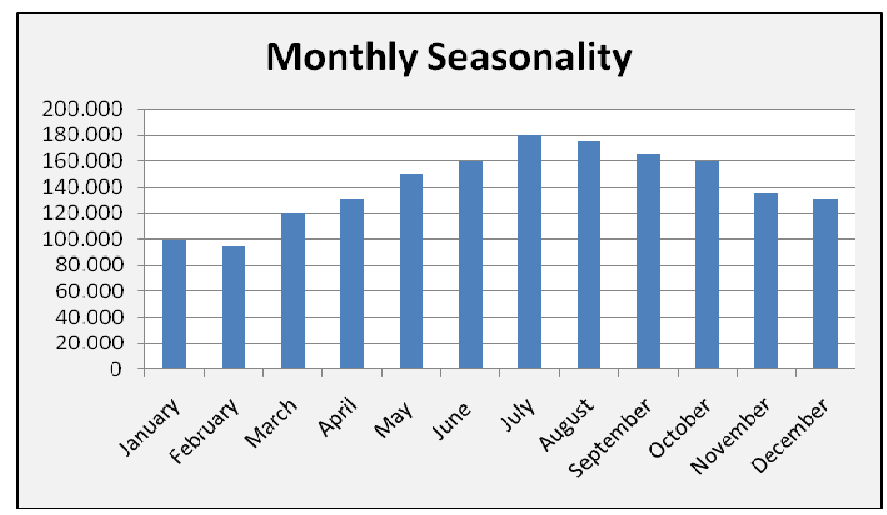

Figure 3: Monthly fluctuation of the number of passengers at Zagreb Airport.

In order to develop the operator model, in this case railway carrier, the elements affecting the model should be defined, and they are called the basic operative elements.

The basic model element is the line that is represented by the infrastructural base and transport service using the respective transport means. When speaking of infrastructure, one thinks of the railway line, in this case, and the stops at which the vehicles stop in order to load and unload passengers.

The model proposed in case of Zagreb Airport can be classified according to ICAO types as light rail model. Since in the concrete case the railway line is along its entire length physically separated from other transport modes, the schedule reliability is very high. The position of the stops has been planned as part of the Zagreb Airport passenger terminal, in its underground section, and in the very centre of Velika Gorica and at the Kvaternik Square in the City of Zagreb.

In this paper, two types of capacities will be described, that affect the carrier model. The transport means capacity represents the number of seats and standing places per train. The transport means are selected depending on the relation operated by a certain line, i.e. the ratio of seating and standing places. Since this is a line which connects the Airport and the city, one has to take into consideration the profile of passengers who are going to use this line. In this case these are going to be mainly passengers with baggage so that the necessary baggage compartments need to be provided. Apart from the airport users, this line would also be used by Airport employees and the population of the town of Velika Gorica who commute to Zagreb. Regarding the two mentioned passenger profiles, the respective line should also provide seating places and standing spaces that cover about $0.75-0.80 \mathrm{~m}^{2}$ per passenger. The number of places depends on the number of passengers who will use the line, headways and the throughput capacity of the railway line. Another type of capacity is precisely the throughput capacity of the line i.e. the number of trains that can be carried by a certain line section within a certain time interval, and depends on the 
infrastructural line characteristics, type of security measures and design (traction) characteristics of the transport means.

According to the carried out survey, $63 \%$ of airport passengers would use rail transport, if available, to leave or arrive to the airport. Analysing the number of passengers arriving by air to the airport and recognizing that $63 \%$ would use rail transport, the estimate says that 112 passengers/hour would use rail as the transport means. This number should be increased by 449 passengers/hour who would travel between Velika Gorica and Zagreb. There are 106 passengers/hour travelling from Zagreb towards the airport, who would continue their journey by air, but this number of passengers also needs to be increased by those who travel to Velika Gorica, which is 449 passengers.

Regarding the vehicles, electric railcars of 300 passengers capacity will operate on the mentioned line. The rolling stock consists of the number of vehicles (required for regular service), vehicles that represent a reserve in case of disturbances during operation, and the number of vehicles that are being maintained or are out of service due to failure. It can be expressed by the formula:

$$
\mathrm{N}_{\mathrm{t}}=\mathrm{N}+\mathrm{N}_{\mathrm{r}}+\mathrm{N}_{\mathrm{m}} \text { (number of trains). }
$$

$\mathrm{N}_{\mathrm{t}}$ - total number of trains,

$\mathrm{N}$ - number of trains that are required for regular service,

$\mathrm{N}_{\mathrm{r}}$ - number of special (extra) trains,

$\mathrm{N}_{\mathrm{m}}$ - number of trains not operating either because of failure or maintenance.

Regarding the number of passengers, lack of uniformity in transportation and headways, two trains are required for regular service. It should be emphasized that purchase of new transport means is necessary which would satisfy the passengers' needs who will mainly travel with bigger pieces of baggage, and therefore the transport means should also be selected on the respective lines. Since this refers to new trains the immobilization percentage is $3 \%$.

The headway is the time interval, usually expressed in minutes, between two arrivals of trains on one line that travel in the same direction, at the same stop or measurement point. From the passengers' aspect the headways should be as short as possible, but from the carriers' perspective it is more cost-efficient to have fewer cars of higher transport capacity than a larger number of cars of lower transport capacity. If the headways are longer than 6 minutes, the recommendation is to take intervals of $10,12,15,20,30$ or 60 minutes because passengers will remember these more easily in this manner.

From the passengers aspects the travel time depends directly on the speed, staying at stops, waiting for the transport means, and time spent for the arrival to the stop. From the operators aspects the turnover time is significant. The turnover time is affected by the speed (technical speed) that is reached between two stops, standing time and time spent at the starting, i.e. end railway station. The technical speed depends on the distances between single stops and car traction characteristics. If the distances are short the vehicle cannot reach the maximal permitted speed on the given section and the travel time consists of the 
time necessary for acceleration and the time necessary for braking. If the distances are sufficient so that the vehicle may reach the maximally permitted speed the travel time consists of the time necessary for acceleration and braking and the time during which the vehicle runs at maximally permitted speed. The time a vehicle spends at the starting i.e. end railway station is necessary for the change of the train staff, required rest for the train staff and possible waiting for alignments in schedule.

In the planned model, the connection of Velika Gorica via airport with the City of Zagreb would be established on two lines. One line would connect Velika Gorica and the Airport and the other one the Airport and the City of Zagreb. These two lines would have one common stop at the Airport terminal. The headway of line A (Zagreb Airport - Zagreb - Zagreb Airport) is 30 minutes, out of which 12 minutes is pure travel time in each direction, whereas time of staying at stops is 3 minutes each. The passengers travelling from Zagreb to Velika Gorica have to wait for 3 minutes at the airport terminal for line B, whereas the passengers travelling from Velika Gorica to Zagreb would wait at the same terminal for line A for 5 minutes. A single-track railway line is planned between Zagreb and Velika Gorica which is the main reason for introducing two lines, both of which have the starting, i.e. destination point at the airport terminal. In the case that the train operation is organized so that the trains operated along the entire Zagreb-Zagreb Airport-Velika Gorica line, the headways would be much longer since the line is a single-track one, and minimally two trains would be necessary, the same as in the described case. Should shorter headways be necessary in the future than the ones mentioned in this paper, then a railway crossing point could be constructed between Zagreb and the Airport, thus increasing the line capacity.

The transport cost of the railway line is included in the airport ticket price, i.e. more precisely in the airport taxes. Furthermore, other users on this line are airport employees or air carriers' employees having their offices at the Airport, and they will have monthly or annual transport documents which enable transport on the mentioned route. The potential users arriving to the Airport as greeters or meeters will have the possibility of purchasing a ticket at every stop.

\section{Conclusion}

In the planning phase of airport development and with the new development study of Zagreb Airport which means the construction of a new terminal and runway, it is necessary to develop a model of railway operator who could satisfy the future demand for capacities and thus alleviate the burden on the one of the busiest roads in Croatia. Regarding the expected growth of passenger traffic at Zagreb Airport in the next 10 years it would not be realistic to expect that it would be cost-efficient to construct a new railway system exclusively for the connection of Zagreb Airport and the city centre. Taking into consideration the number of citizens of Velika Gorica and the number of passengers daily commuting to Zagreb from Velika Gorica, the railway connection to Zagreb Airport is to be extended to the centre of Velika Gorica. Having in mind the 
traffic congestion of the single route that connects Velika Gorica and the airport with the city, a large number of passengers is expected to use the alternative connection with the city, in this case - the railway line.

To satisfy the variable demand and achieve good utilization of the offered capacity, service must be tailored to cover the demand as closely as possible. This can be done in three different ways:

1. Changing headways - shortening them (higher frequency) during peaks;

2. Using different TU sizes / capacities, such as different train configurations (number of cars);

3. Operating TUs on certain sections of the line only ("short-turn trains"), so that the protruding topography peaks are covered by small additional TU capacity boxes.

The proposed light rail model provides the reliability in the schedule since along the entire section the model is completely separated from other transport modes and reduces significantly the travel time which can today be realized only by road. Because of the growth in the number of passengers at the Airport of $9 \%$ annually, and since, according to the surveys, more than half of the passengers would use railway transport from the Airport to the City of Zagreb, a development of a model of a railway operator considering Zagreb AirportZagreb city centre relation has to be considered as soon as possible.

\section{References}

[1] Antonin Kazda, Robert E. Caves: Airport design and operation, Elsevier Linacre House, Jordan Hill, Oxford OX2 8DP, U.K. Radarweg 29, PO Box 211, 1000 AE Amsterdam, The Netherlands, 2008

[2] International Air Transport Association, Airport Development Reference Manual, Montreal, 2004

[3] Norman Ashford, Paul H. Wright: Airport Engineering, Third Edition, Wiley-Interscience Publication, 1992

[4] Zračna luka Zagreb: Annual Report 2003-2008, Zagreb

[5] Vuchic, V.R., Urban Transit: Operations, Planning and Economics, http://eu.wiley.com (product Cd-0471632651)

[6] Badanjak, D., Bogović, B., Jenić, V., Organization of railway traffic, Faculty of Transport and Traffic Sciences, Zagreb, 2006.

[7] Statistical Analyses, Hrvatske Ceste d.o.o, http:/www.hrvatske-ceste.hr/ brojenje-prometa.htm

[8] Statistical Analyses, Zagrebacki Elektricni Tramvaj, http://www.zet.hr 